\title{
Presentación. Publicaciones periódicas del siglo XX: aspectos emergentes, miradas latinoamericanas
}

\section{Presentation. Periodicals of the 20th Century: Emerging Aspects, Latin American Views}

El siglo XX latinoamericano fue el tiempo de las revistas y los diarios en papel. Aunque habían tenido una función primordial en la vida cultural y política de las ciudades desde mucho antes, fue al ritmo de la modernización cuando cobraron un auge y una dimensión social de mayor alcance. El declive de los "tiempos de papel" coincidió con la expansión de la red electrónica que empezó a atravesar los espacios locales y nacionales con publicaciones periódicas que desde entonces dan a leer en formato digital la producción contemporánea de textos e imágenes. En 1999 el libro colectivo La cultura de un siglo: América Latina en sus revistas reunió un conjunto de trabajos presentados por especialistas en el encuentro del mismo nombre realizado dos años antes en Buenos Aires. En explícito balance de la centuria que terminaba, ponía el foco en revistas consideradas imprescindibles para la historia literaria latinoamericana del siglo XX. Era un indicio de lo que en la siguiente década se definiría como un área de estudios nueva y en expansión, que iría ensanchando su radio y sus contornos para incluir otro tipo de publicaciones periódicas y otros asuntos, además del literario inicial. El interés creciente y las 
posibilidades abiertas por la red electrónica confluyeron en la organización de sitios web que empezaron a poner a disposición archivos digitales de antiguos periódicos y revistas para su conocimiento y estudio.

El auge de los periódicos había tenido lugar antes en las regiones centrales de Occidente. Con el triunfo del impreso industrial hacia fines del siglo XIX, las ciudades europeas contaban con numerosos lectores y habían incrementado la cadena de intermediarios para la producción y distribución de formatos accesibles y perecederos como diarios, revistas y folletos donde, más que en los libros, se dio la escritura y la lectura a gran escala. En las ciudades latinoamericanas, la ampliación relativa del público lector y el desarrollo de la industria cultural se dieron en el marco de procesos diferenciados y heterogéneos, frecuentemente interrumpidos por las penurias económicas y políticas de un continente caracterizado por la desigualdad social estructural. Como sabemos, la transformación de la comunicación al ritmo de la modernización fue y sigue siendo desigual en América Latina y sería un error tan grueso ignorar los modelos metropolitanos como depositar únicamente ahí una explicación (Ramos). En distintos lugares, las publicaciones adoptaron inflexiones locales sobre matrices transnacionales, mientras la circulación de ideas y lenguajes estéticos, los formatos y los recursos técnicos traspasaban fronteras al ritmo del capitalismo global.

Producidas en el cruce de lógicas artísticas, políticas, profesionales y mercantiles, resultan un espacio insoslayable para releer la historia y las configuraciones de nuestra cultura. En el dossier "Publicaciones periódicas y redes culturales en América Latina" de Catedral Tomada (2018) varias miradas contribuyen a ampliar su conocimiento, dando relevancia a aspectos antes desatendidos o apenas esbozados, y renovando el interés en algunas constantes.

Una de ellas es la dimensión transnacional y a la vez localizada de las publicaciones. El proceso dinámico de intercambios, así como las formas de negociar activamente desde Latinoamérica los términos de la participación en lo mundial se hacen presentes en el artículo de Antonia Viu (2018), quien sostiene que al seleccionar y recortar de la prensa internacional, las "revistas de revistas" 
cubanas y argentino-chilenas de las décadas de 1930 y 1940 configuraron nuevas cartografías donde los intelectuales latinoamericanos se pensaron a sí mismos, adhiriendo a formaciones ideológicas o estéticas producidas en los centros de Occidente, y generando desplazamientos al reeditar fragmentos en contextos culturales locales. En su trabajo sobre la recepción sudamericana de M. Proust, Margarita Merbilháa (2018) muestra el rol de la revistas culturales argentinas de los años veinte como lugares de manifestación de una sensibilidad nueva y de nociones sobre el lugar del arte, así como la apropiación de ideas del escritor francés desde una experiencia periférica respecto de los centros europeos. Por su parte, Federico Brugaletta estudia Cristianismo y Sociedad, una revista iniciada en Montevideo a comienzos de los años sesenta, vinculada a una red de alcances trasnacionales tanto a escala continental como global, que se distribuía en más de catorce países de Latinoamérica a través de una red de agentes y librerías vinculadas al protestantismo, y que sufrió un obligado exilio por razones políticas que la llevó a reiniciar una segunda etapa en Buenos Aires en 1974 donde continuó hasta su prohibición por la dictadura argentina.

Nuevas exploraciones sugieren que hay todo un campo por explorar en las formas de articulación entre distintos subsistemas y soportes del sistema editorial: entre las revistas y los diarios, por un lado, y de ambos con los libros, por otro. El artículo de Marco Frank y Alexandra Pita González (2018) sobre la red estridentista indica lateralmente que, junto al rol central de las revistas de ese movimiento, como Irradiador y Horizonte, también los periódicos de amplia circulación -como El Universal y El Universal Ilustrado- tuvieron un papel en la difusión y amplificación de las acciones, discursos y figuras de la vanguardia. El artículo de María de los Ángeles Mascioto (2018) sobre la participación de David Alfaro Siqueiros en la Revista Multicolor de los Sábados de Buenos Aires, plantea que la escritura ficcional del muralista mexicano y su propuesta de arte político resultaron afectadas por el perfil empresarial del diario Crítica, que editaba esta "revista" como suplemento semanal. 
Otras dos cuestiones de interés atraviesan de manera creciente, más o menos focalizada y explícita, las miradas actuales sobre las publicaciones periódicas: su materialidad como objetos impresos y su dimensión exhibitiva.

\section{Materialidad}

En un libro notable y ya histórico, Raymond Williams (1961) planteó la importancia de la prensa en la expansión general de la cultura en Inglaterra, cuyo desarrollo a lo largo de varios siglos había sido paralelo a la ampliación del público lector. Ahí discutió algunos presupuestos de las historias de la prensa. Entre ellos, la idea de que las principales transformaciones se debían a políticas educativas por las cuales la mayoría de la gente había aprendido a leer. Sin negar ese factor fundamental, Williams ponía el foco en un aspecto hasta entonces no atendido. Empezaba por recordar que en su origen el periódico había sido la creación de una clase de comerciantes, sirviendo a esa clase para la distribución de las noticias comerciales (que a la vez aseguraban sustento a sus páginas), al mismo tiempo que satisfacía intereses más amplios: la formación de opinión, la diseminación de costumbres e ideas. Para entender las trasformaciones de la prensa, decía Williams, había que reponer los aspectos económicos y técnicos que la habían hecho posible y le habían dado determinados rasgos: el descenso del precio por la inclusión de avisos, los avances en los sistemas de impresión, la mejora de las vías férreas, entre otros. La orientación de un periódico y el tipo de material que ofrecen sus páginas se vincula con las inclinaciones ideológicas o estéticas de redactores y directores, pero también con su base económica de sustentación, que supone entre otras cosas el perfil de cierto público, consumidor potencial no solo de sus artículos sino también de sus anuncios. Es indispensable, enseñaba Williams, tener en cuenta la organización social y económica, tanto de la sociedad en la que surge como de la publicación misma: preguntarse cómo se sustenta económicamente, si paga o no las colaboraciones, si incorpora anuncios, con qué recursos técnicos cuenta, si 
dispone de una red de transportes para su distribución, si se vende por suscripción, en kioscos o en librerías.

Estas cuestiones que hoy parecen elementales no siempre tuvieron una presencia significativa en los estudios sobre publicaciones periódicas. Hoy resulta infrecuente abordarlas atendiendo solo a las ideas o discursos estéticos que ponen en circulación, sin considerar la base económica que explica cuestiones diversas entre las que se cuentan su amplia o reducida circulación, su continuidad en el tiempo o interrupción, entre otras. Así, por ejemplo, el estudio de una publicación militante como Cuadernos Internacionales por Karina Jannello (2018) considera indispensable desplegar sus concepciones acerca de la función de los intelectuales en la sociedad y su compromiso con las ideas, tanto como consignar cuestiones que a primera vista podrían parecer menos relevantes, como su formato y diagramación cercanos al libro, o el hecho de que la revista fuera financiada por el grupo que la promovía, sin anuncios publicitarios de ningún tipo, con una frecuencia cuatrimestral en los primeros tres números, mientras que el cuarto demoró todo un año y fue el último en salir. La conexión entre esos datos sugiere condiciones de producción que sin duda signaron el destino del proyecto. Federico Brugaletta (2018) saca provecho de la observación de los rasgos materiales en su investigación sobre Cristianismo y Sociedad, órgano de difusión de un protestantismo de izquierda en Montevideo. Da cuenta de los debates intelectuales que tejieron sus páginas y de cuestiones vinculadas al diseño, la producción y circulación. La atención a esos aspectos permite advertir características de formato que revelan que la revista servía a sus lectores para el estudio, lo que se corrobora en ejemplares consultados, con huellas de esas prácticas en subrayados y anotaciones en los márgenes que aportan indicios de usos asociados a lecturas de formación.

Los rasgos materiales y los recursos técnicos que dan cuerpo a diarios y revistas son aspectos que las investigaciones actuales incorporan de manera significativa. La historia de la edición y de la cultura impresa, y la sociología de los textos (Mc Kenzie; Chartier) han enriquecido la perspectiva. Las publicaciones periódicas han dejado de ser meros soportes de ideas (fuentes documentales para el 
estudio de autores o de procesos históricos) para transformarse en objetos de estudio en sí mismas, con rasgos ideológicos y estéticos, visuales y textuales, de diseño e impresión indispensables para comprender su sentido como publicación. También se ha vuelto más evidente su elaboración colectiva, con la intervención de escritores, directores, jefes de redacción, periodistas, fotógrafos, ilustradores, anunciantes, diseñadores, correctores; una pluralidad de actores que orientaron o dictaron posturas y formas de comprensión de los materiales que entregaban a los lectores, quienes a su vez se apropiaron de ellos, construyendo significados variables y a veces no previstos.

Varios de esos aspectos se vuelven centrales en el artículo de Antonia Viu (2018) sobre las revistas de recortes latinoamericanas, donde la "digestión" de lo leído resulta una forma de producción por ensamblaje de fragmentos. Un objeto y un procedimiento material -el recorte- adquiere entonces relevancia mayor al manifestar su carácter múltiple como objeto moderno, como tecnología de archivo y como práctica editorial.

\section{Dimensión exhibitiva}

Puestas en vertical en los sitios web, las publicaciones periódicas hacen más patente uno de sus rasgos definitorios: tanto en "tiempos de papel" como en los nuevos soportes del siglo XXI, ellas son dispositivos de exposición privilegiados, entornos para poner a la vista, periódicamente, materiales en el ámbito público (Rogers, 2019 en prensa).

Esa dimensión tiene un correlato en la publicidad, cuya emergencia histórica coincidió con la de prensa, disponible para un público amplio gracias a ella, facilitando la promoción de bienes y servicios junto a los textos e imágenes. Desde siempre los diarios y las revistas tienden a superponer, de manera más o menos directa y evidente, lo que muestran y lo que anuncian. 
Considerar ese aspecto implica atender a una dimensión performativa que puede o no coincidir con las declaraciones explícitas. Al margen de sus propósitos declarados, las publicaciones periódicas intervienen de manera efectiva en el reparto de lo visible y lo legible en la esfera pública y en el mercado de bienes simbólicos. Pensar sus razones éticas, estéticas, ideológicas o comerciales -sugiere Philippe Hamon (1989)- requiere percibirlas como arquitecturas semióticas articuladas y jeraquizadas, construidas a partir de cálculos previos de espacios gráficos, costos de producción, tiempos de lectura, entre muchos otros.

La dimensión exhibitiva es constatable en su propia materialidad e inseparable de su impulso hacia lo público. Casi siempre implícita en los estudios sobre diarios y revistas, empieza a adquirir relevancia mayor en un tiempo en que -como insiste con razón Didi-Huberman- "estar a la vista" resulta un objetivo fundamental de la vida pública.

Algo de esto aparece en primer plano en el artículo de Cristina Moyano Barahona (2018) sobre las huellas del feminismo en revistas académicas chilenas, dispositivos de visibilización de las condiciones de subalternidad, explotación y exclusión de las mujeres entre 1980 y 1990. Asimismo, en su investigación sobre Irradiador y Horizonte, Marco Frank y Alexandra Pita González (2018) muestran la importancia de esas revistas para exponer la actividad y las ideas del grupo estridentista. Algo similar se observa en el estudio sobre la revista Imán, cuyo único número Claudio Maíz (2018) considera como uno de los primeros lugares que dio a leer textos de autores que iniciarían una renovación en la narrativa latinoamericana. Por su parte, Verónica Delgado (2018) aborda las estrategias del periódico La Gaceta Literaria desde 1927 para hacer visible la vida de las letras, mediante secciones orientadas explícitamente por su director a "exponer y meter por los ojos al público" la producción literaria española, incluso con una sección titulada "Escaparate de libros", además de las imágenes fotográficas de autores y las diversas formas de publicidad del mundo editorial. En su investigación sobre dos escritores brasileños en Buenos Aires en las primeras décadas del siglo XX, Joao Paulo de Souza Rodrigues (2018) observa que en ocasión de la visita de Paulo 
Barreto y Julia López de Almeida, los diarios argentinos funcionaron como vidrieras que, a través de textos y fotografías, mostraron no solo la sociabilidad intelectual sino también fragmentos de prosa ficcional que dieron a conocer la producción escrita de los visitantes, generando así la difusión de esas figuras y de su literatura. La dimensión a la que me refiero surge implícitamente también de la lectura del trabajo de César Zamorano Díaz (2018) sobre la revista Manuscritos como forma de resistencia en tiempos de la dictadura chilena, lo que da pie para pensar la relación intensa y paradójica entre el propósito de visibilización de una vida cultural emergente y las condiciones de censura, persecución y control cultural que dictaban qué y cómo podía, o no, exponerse públicamente, en un tiempo en que, por efecto del miedo o de la represión directa, muchas actividades fueron silenciadas y una cantidad enorme de impresos fueron destruidos o escondidos.

Las publicaciones periódicas son dispositivos de exposición de textos e imágenes, de ideas y figuras que se inscribirán en la vida social y en la memoria cultural por un tiempo variable según la intensidad y frecuencia de su aparición en diarios y revistas. Considerar ese aspecto implica pensar qué y cómo en ellas se expone, se subexpone o se sobreexpone. Orientar su estudio en ese sentido equivale a preguntar cómo intervienen en el reparto de lo visible y lo legible, y cómo se materializan sus estrategias de visibilización en arquitecturas de aparición periódica.

\section{Accesibilidad e investigación}

En las últimas décadas han cambiado las formas de acceso a las publicaciones del pasado para su conocimiento y estudio. Tiempo atrás algunas revistas fueron "reeditadas" con un criterio basado en la reproducción parcial o total de sus textos, con escaso material gráfico y diagramación propia del formato libro. Esas rediciones, cuyo valor radica en haber puesto en circulación materiales hasta entonces de difícil acceso, otorgaban un predominio casi exclusivo a lo textual, 
eludiendo los aspectos gráficos y visuales. En ese sentido, las ediciones facsimilares en papel o a través de repositorios digitales de acceso abierto implican una diferencia fundamental. Estas opciones no suponen acceder sin mediaciones a un objeto idéntico al de su estado previo porque modifican las condiciones de circulación y recepción (la edición facsimilar suele dar a leer en un mismo tomo los números que antes se ofrecían por separado, generando una sensación de conjunto previamente inexistente; el repositorio digital permite observar la tipografía, la diagramación, las imágenes y el diseño de página, no el tipo de papel o el tamaño), pero implican un salto cualitativo, transformador en varios sentidos. La web supone una simplificación del acceso y una mayor disponibilidad (resta verificar su correlato más o menos significativo en relación con la cantidad de estudios que actualmente eligen su objeto entre las publicaciones digitalizadas). Sin duda, además, el interés creciente a causa del complejo mundo que se despliega en ellas, y las posibilidades abiertas por la mayor accesibilidad ofrecen nuevos desafíos, como si algunos rasgos propios del objeto -su intrínseca heterogeneidad y su producción colectiva- se proyectaran ahora como un reto a las formas de investigación: "el trabajo colaborativo que supone el estudio de revistas -observa César Zamorano Díaz (Escrituras en tránsito, 2018) - implica sin duda una disposición diferente, de apertura entre disciplinas, de ampliación de miradas, capaz de abordar la maravillosa fuente de nuestras reflexiones teóricas, artísticas y políticas que se dan cita en las revistas". Nuestro interés por un objeto de investigación como las publicaciones periódicas, que inclina al trabajo colaborativo y obliga todo el tiempo a cruzar fronteras, no parece ajeno a la necesidad de trasponer límites disciplinares para explorar zonas lindantes que permiten pensar lo que nos falta. Y tal vez tampoco sea ajeno al deseo de ser parte de una construcción en común y latinoamericana. 


\section{Bibliografía}

Artundo, Patricia M. "Reflexiones en torno a un nuevo objeto de estudio: las revistas". Actas del IX Congreso Argentino de Hispanistas. La Plata: Universidad Nacional de La Plata, 2010. Disponible en: http://ixcah.fahce.unlp.edu.ar/actas/artundo-patricia-m.pdf/view

Barbier, Frédéric y Bertho Lavenir, Catherine. Historia de los medios de Diderot a Internet. Buenos Aires: Colihue, 2007.

Brugaletta, Federico. “Cristianismo y Sociedad (1963-1973). Protestantismo de izquierda en la historia reciente de América Latina”. Catedral Tomada. Revista de Crítica Literaria Latinoamericana $\mathrm{n}^{\circ} 11$. Pittsburgh: University of Pittsburgh (2018).

Chartier, Roger. "El sentido de las formas". Iber: revista europea de libros $\mathrm{n}^{\circ} 1$ (1989), 8-10.

Delgado, V, y Rogers (ed). Tiempos de papel. Publicaciones periódicas argentinas (XIX-XX). La Plata: Universidad Nacional de La Plata, 2016. Disponible en: http://www.memoria.fahce.unlp.edu.ar/libros/pm.488/pm.488.pdf

Delgado, Verónica, Alejandra Mailhe y Geraldine Rogers (eds). Tramas impresas. Publicaciones periódicas argentinas (XIX-XX). La Plata, Universidad Nacional de La Plata. 2014. Disponible en: https://www.libros.fahce.unlp.edu.ar/index.php/libros/catalog/book/3 $\underline{3}$

Delgado, Verónica. “Algo más sobre el Meridiano editorial hispanoamericano (1927-1928)". Catedral Tomada. Revista de Crítica Literaria Latinoamericana $\mathrm{n}^{\circ} 11$. Pittsburgh: University of Pittsburgh (2018).

Didi-Huberman, Georges. Pueblos expuestos, pueblos figurantes. Buenos Aires: Manantial, 2014. 
Ehrlicher, Hanno/ Rissler-Pipka (eds.). Almacenes de un tiempo en fuga. Revistas culturales en la modernidad hispánica. Aaschen: Shaker Verlag, 2014.

Frank, Marco y Alexandra Pita González. "Irradiador y Horizonte: revistas de un movimiento de vanguardia y una red estridentista". Catedral Tomada. Revista de Crítica Literaria Latinoamericana ${ }^{\circ} 11$. Pittsburgh: University of Pittsburgh (2018).

Hamon, Philippe. Expositions. Littérature et architecture au XIXe siècle. Paris: José Corti, 1989.

Janello, Karina. "Benito Milla: un Ulises desgraciado en el Río de la Plata. De Cuadernos Internacionales a Mundo Nuevo, del socialismo libertario al humanismo antibelicista". Catedral Tomada. Revista de Crítica Literaria Latinoamericana $\mathrm{n}^{\circ} 11$. Pittsburgh: University of Pittsburgh (2018).

Maíz, Claudio. "El acierto en el fracaso. La revista Imán (1931), un episodio de la historia literaria latinoamericana". Catedral Tomada. Revista de Crítica Literaria Latinoamericana $\mathrm{n}^{\circ} 11$. Pittsburgh: University of Pittsburgh (2018).

Mc Kenzie, Donald. Bibliografía y sociología de los textos. Madrid: Akal, 1999. Merbilhaá, Margarita. "La recepción temprana de Marcel Proust en el espacio de revistas culturales argentinas de los años Veinte". Catedral Tomada. Revista de Crítica Literaria Latinoamericana $\mathrm{n}^{\circ} 11$. Pittsburgh: University of Pittsburgh (2018).

Moyano Barahona, Mónica. "Escrituras de mujeres, las huellas del feminismo en las revistas de los Centros Académicos Independientes, Chile 19801990". Catedral Tomada. Revista de Crítica Literaria Latinoamericana $\mathrm{n}^{\circ} 11$. Pittsburgh: University of Pittsburgh (2018).

Patiño, Roxana y Jorge Schwartz (eds.). Revistas Literarias/Culturales latinoamericanas. Revista Iberoamericana, 208-209, Pittsburgh juliodiciembre 2004.

Ramos, Julio. Desencuentros de la modernidad en América Latina. Literatura y política en el siglo XIX. México: FCE, 1989. 
Rogers, Geraldine. "Las publicaciones periódicas como dispositivos de exposición”. En Verónica Delgado y Geraldine Rogers (eds.). Revistas, archivo y exposición. Publicaciones periódicas argentinas del siglo XX. La Plata: Universidad Nacional de La Plata (2019, en prensa).

Sosnowski, Saúl (ed.). La cultura de un siglo: América Latina en sus revistas. Buenos Aires: Alianza, 1999.

Viu, Antonia. "Selección y digestión en "revistas de revistas" latinoamericanas (1930-1950)".Catedral Tomada. Revista de Crítica Literaria Latinoamericana $\mathrm{n}^{\circ} 11$. Pittsburgh: University of Pittsburgh, 2018.

Williams, Raymond. The Long Revolution London: The Hogarth Press, 1992 [1961]

Zamorano Díaz, César. "Revista Manuscritos: nuevas formas de resistencia durante la Dictadura chilena”. Catedral Tomada. Revista de Crítica Literaria Latinoamericana $\mathrm{n}^{\circ} 11$. Pittsburgh: University of Pittsburgh (2018).

Zamorano Díaz, César. Escrituras en tránsito. Revistas y redes culturales en América Latina. Santiago de Chile, Ed. Cuarto Propio, 2018. 